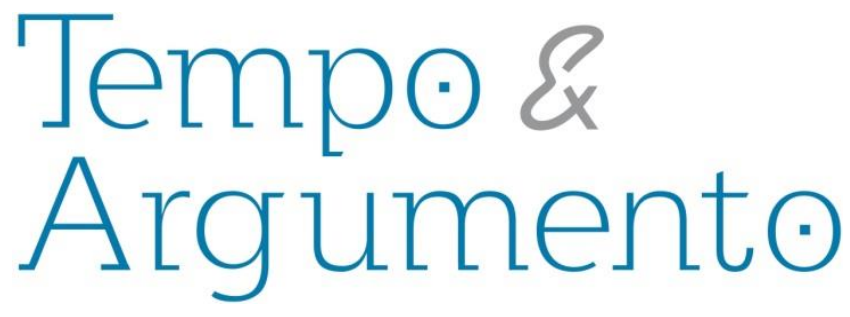

\title{
Xô, fado! Nacionalismo e antilusitanismo na terra do samba ${ }^{1}$
}

\begin{abstract}
Resumo
Nacionalismos de todas as colorações políticas pululavam mundo afora durante a década de 30 do século passado. Aqui, do lado de baixo do Equador, não foi diferente. No Brasil, em particular, tanto à direita como à esquerda do espectro ideológico nacional, manifestações de matriz nacionalista se fizeram sentir nos mais distintos campos, inclusive na área artística. Foi a época em que se assistiu à invenção do samba como ícone musical da nação. Em meio a esse processo, certos compositores populares moveram um combate aos estrangeirismos em geral. O fado, terceiro gênero musical "estrangeiro" mais gravado no país, ficou, então, sob a alça de mira de determinados críticos. Um inflamado antilusitanismo chegou a se expressar em estreita ligação com um sentimento antifadista. Este artigo se propõe, a partir daí, a mapear tais manifestações, tendo por foco, sobretudo, a produção do jornalista, poeta e compositor Orestes Barbosa, um dos parceiros de Noel Rosa. Ao mesmo tempo, busca inserir as lutas de representações travadas em nome do samba em redes de interlocução informais que desde o século XIX exprimiam sua hostilidade seja em relação a Portugal ou ao fado. Neste último caso, importa observar que ele enfrentou também sérias rejeições em terras portuguesas até impor-se como "fiel intérprete da alma lusitana".
\end{abstract}

Palavras-chave: Fado. Samba. Música Popular - Brasil. Música Popular - Portugal. Lutas de Representações.

\author{
Adalberto de Paula Paranhos \\ Doutor em História pela Pontifícia \\ Universidade Católica de São Paulo (PUC/SP). \\ Professor do Instituto de Ciências Sociais e \\ dos Programas de Pós-graduação em História \\ e em Ciências Sociais da Universidade Federal \\ de Uberlândia (UFU). \\ Uberlândia, Minas Gerais - Brasil \\ akparanhos@uol.com.br
}

\section{Para citar este artigo: \\ PARANHOS, Adalberto. Xô, fado! Nacionalismo e antilusitanismo na terra do samba. Tempo e Argumento, Florianópolis, v. 9, n. 22, p. 44 - 69, set./dez. 2017.}

\section{DOI: $10.5965 / 2175180309222017044$}

http://dx.doi.org/10.5965/2175180309222017044

\footnotetext{
${ }^{1}$ Este texto é um desdobramento do projeto "Fado, um 'inimigo nacional' na terra do samba? Lutas de representações no Brasil dos anos 1930", desenvolvido, desde março de 2017, com bolsa de produtividade em pesquisa do CNPq.
} 


\title{
Shoo, fado! Nationalism and anti- Portuguese feelings in the land of samba
}

\begin{abstract}
In the 1930s, there was an abundance of nationalisms of all political hues. Here, south of the Equator, it was similar. In Brazil particularly, on both the right and left sides of the national ideological spectrum, these nationalistic manifestations emerged in the most different fields, including art. This was when the invention of samba as the musical icon of the nation took place. In the midst of this process, a few songwriters engaged in a combat against everything foreign. Thus, certain critics targeted fado, the third most recorded "foreign" musical genre in the country. A passionate antiPortuguese attitude was even expressed that was tightly linked with an anti-fado feeling. In this framework, this article aims at mapping these manifestations, focusing mainly on the journalist, poet, and songwriter Orestes Barbosa's production, which was one of Noel Rosa's musical partners. At the same time, the text situates the representations struggles waged on behalf of samba against fado in informal discussion networks that had expressed, since the 19th century, their hostility toward either Portugal or fado. As to this latter music genre, it is important to note that it also faced serious rejection in Portugal before it established itself as a "faithful interpreter of the Portuguese soul".
\end{abstract}

Keywords: Fado. Samba. Popular Music - Brazil. Popular Music - Portugal. Representations Struggles.

Bafejado pelos bons ares que sopravam em Oeiras, no verão de 2014, António Zambujo pôs os pés nos Atlantic Blue Studios para registrar em CD o samba-canção "Último desejo", que leva a assinatura de Noel Rosa. ${ }^{2}$ Esse admirador confesso de João Gilberto, uma das vozes masculinas mais enaltecidas do fado nos últimos tempos, imprime a seu canto um estilo mais contido, acompanhando-se de uma guitarra clássica que faz par com uma guitarra portuguesa, escorado ainda num baixo português, entre

\footnotetext{
${ }^{2}$ Até por uma questão de precaução metodológica, é preciso não confiar às cegas no que se lê nos selos dos discos. No caso dessa composição, ela é identificada expressamente, no seu registro original, de 1938, como samba, embora, a rigor, seja um samba-canção. Ouvir "último desejo", com Aracy de Almeida.
} 
Nesse tributo ao poeta da Vila, talvez António Zambujo sequer tenha se dado conta de que, por essa via, ele tocava num nervo exposto das lutas de representações travadas no Brasil da década de 1930. Por essa época, na trincheira dos compositores nacionalistas, empenhados na invenção do samba como ícone musical do Brasil, buscavase ordenar o discurso de tal modo que se instituíam geografias sonoras bem delimitadas. Noel Rosa, ao lado de outro sambista de grande expressão, Assis Valente, um dos criadores preferidos por Carmen Miranda, ocupava um posto de destaque no combate aos modismos dos estrangeirismos nas suas mais diferentes manifestações, incluído aí o campo musical.

Um parceiro de Noel, em particular, o poeta e jornalista Orestes Barbosa, primava, então, pelo antilusitanismo. Às suas inflamadas declarações contra tudo o que remetia a Portugal, somava-se o seu desprezo pelo fado, por ele achincalhado como um gênero musical vil, que, apesar ou por causa mesmo da sua ressonância no Brasil, conspirava contra o que existia de melhor, musicalmente falando, neste país.

Se hoje António Zambujo como que pode selar, de uma vez por todas, o armistício entre o mundo do samba e o mundo do fado, dando de ombro, na prática, a essas lutas simbólicas, o que se percebe, ao recuarmos no tempo, é que nem sempre tudo foram flores ao longo dessa convivência. Isso é atestado por uns tantos desencontros entre eles, que, de resto, alimentavam-se de uma das pontas da tradição que opôs, aqui e ali, lusos e brasileiros. Afinal, para além daqueles que cultivavam as boas relações entre Brasil e Portugal, outras falas - menos indulgentes quanto ao julgamento do nosso passado colonial e sua herança - insistiam em engrossar o coro dos descontentes. É disso que me proponho a tratar neste artigo, que amplifica o campo de visão do tema a ponto de recolher também manifestações antifadistas oriundas de terras lusitanas e que condenavam os enfados do fado. Pretendo, portanto, inserir as lutas de representações desencadeadas em nome do samba em redes de interlocução informais que desde o século XIX exprimiam sua hostilidade seja em relação a Portugal ou ao fado. Neste último 


\section{Em cena, as lutas de representações}

Nos anos 1930, em especial, uma série de representações desfilou sob os nossos olhos procurando expressar o significado do samba e do fado. Isso me coloca diante de uma preocupação básica da História Cultural, tal como concebida, entre outros, por Roger Chartier. Como se sabe, ela põe em evidência, sobretudo, que a leitura da realidade obedece sempre a uma determinada construção, que é, no fundo, uma representação. E, no emaranhado de representações, emergem campos tensionados por perspectivas e interesses distintos. Como num cabo de guerra, eles se embrenham em lutas de representações, como as que envolveram o samba e o fado.

Daí ressaltar Chartier (1990, p. 17):

As percepções do social não são de forma alguma discursos neutros [...] Por isso esta investigação sobre as representações supõe-nas como estando sempre colocadas num campo de concorrências e de competições cujos desafios se enunciam em termos de poder e de dominação. As lutas de representações têm tanta importância como as lutas econômicas para compreender os mecanismos pelos quais um grupo impõe, ou tenta impor, a sua concepção do mundo social, os valores que são os seus, e o seu domínio. Ocupar-se dos conflitos de classificações ou de delimitações não é, portanto, afastar-se do social como julgou durante muito tempo uma história de vistas demasiado curtas -, muito pelo contrário, consiste em localizar os pontos de afrontamento tanto mais decisivos quanto menos imediatamente materiais.

Aliás, uma das referências capitais no pensamento de Chartier, o sociólogo Pierre Bourdieu (2002, cap. V), ao discutir o par conceitual identidade e representação, já advertira anteriormente para a relevância das lutas de representações. Ele salientara a necessidade "de se incluir no real a representação do real ou, mais exatamente, a luta das representações”, pois a “"realidade' [...] é o lugar para uma luta permanente para definir a 'realidade"”, o que supõe uma "luta para fazer existir ou 'inexistir' o que existe” (id., p. 
113 e 118). Isso se desdobra num outro texto (sobre a representação política) no qual Bourdieu (id., cap. VII) acentua que

A força das ideias [...] mede-se, não como no terreno da ciência, pelo seu valor de verdade (mesmo que elas devam uma parte da sua força à sua capacidade para convencer que ele detém a verdade), mas sim pela força de mobilização que elas encerram, quer dizer, pela força do grupo que as reconhece, nem que seja pelo silêncio ou pela ausência de desmentido, e que ele pode manifestar recolhendo as suas vozes ou reunindo-as no espaço. (BOURDIEU, 2002, p. 185)

A força dessa ou daquela ideia sobre o samba ou o fado não é, todavia, produto de uma iniciativa solitária ou obra que carrega uma assinatura simplesmente individual. Por outras palavras, ao interpelarmos o passado e o presente vivido por Orestes Barbosa, verificamos que o seu antilusitanismo e o seu antifadismo, por exemplo, são como fios de uma meada que não se desembaraçam facilmente. Ambos estavam enredados, quer ele tivesse consciência disso ou não, numa rede autoral que comporta uma interlocução polifônica com o que se escreveu e se falou sobre o fado e os portugueses. E os laços dessa rede embaraçam concepções forjadas tanto no Brasil como em Portugal, tecendo um campo de reflexões habitado pelo dialogismo.

O que se passa, de modo geral, com as ideias, afeta também, é lógico, as canções. Parto, assim, do princípio de que canção alguma é uma ilha, mantida em regime de clausura, como se fosse possível cortar os fios que a ligam a outras canções e a mil e um discursos e referências sociais. Sem que se perca de vista sua singularidade, quando alargamos a escala de observação de um artefato cultural, pode-se constatar que, dialeticamente, tudo se acha em interconexão universal, como que dialogando entre si.

\footnotetext{
3 Numa interpretação elástica dessa passagem, eu diria que nela ressoa, de alguma maneira, a concepção soreliana do mito como valor de ação, como valor motor, de ordem pragmática, mais ou menos independentemente de seu valor de verdade (SOREL, 1992, cap. IV). Minha análise sobre o mito segundo George Sorel, que associo ao mito da doação da legislação trabalhista por Getúlio Vargas, consta de PARANHOS, 2007, cap. 1. Por outro lado, a respeito da “força das ideias", parece-me pertinente relacioná-la com certas formulações de Karl Marx e Antonio Gramsci. Como destaca o filósofo italiano, convém "recordar a frequente afirmação de Marx sobre a 'solidez das crenças populares' como elemento necessário de uma determinada situação. [...] Outra afirmação de Marx é a de que uma persuasão popular tem, com frequência, a mesma energia de uma força material, ou algo semelhante, e que é muito significativa". (GRAMSCI, 2001, p. 238).
} 
Nessa linha de raciocínio, tomo como ponto de partida as contribuições de Mikhail Bakhtin contidas em seus estudos sobre dialogismo ou intertextualidade. ${ }^{4} \mathrm{E}$ aqui, mais do que uma alusão genérica ao princípio dialógico constitutivo de toda e qualquer linguagem e de todo e qualquer discurso, apelo para o uso dessa ferramenta teórica e metodológica para demarcar o caráter socialmente ampliado de determinadas ideias e representações em torno do samba e do fado. Esse processo autoral polifônico se conecta, por outras vias, com o que viria a sustentar Michel Foucault em um de seus célebres escritos sobre “O que é um autor". Ao referir-se, por exemplo, ao dramaturgo Racine, ele, com base em Lucien Goldmann, enfatiza que

fui levado a mostrar que Racine não é sozinho o único e verdadeiro autor das tragédias racinianas, mas que estas nasceram no bojo do desenvolvimento de um conjunto estruturado de categorias mentais que era obra coletiva, o que me levou a encontrar como "autor" dessas tragédias, em última instância, a nobreza de toga, o grupo jansenista e, no interior deste, Racine como indivíduo particularmente importante. (FOUCAULT, 2009, p. 290)

\section{O cruzamento do antilusitanismo e do antifadismo}

Levando em conta as considerações anteriores, Orestes Barbosa, historicamente situado, não se constituía num franco atirador que remoía, isolado, seu antilusitanismo e seu antifadismo. Por ora, calcado numa pesquisa meramente exploratória, é possível detectar exemplos que corroboram tal afirmação. Dessa forma, vislumbram-se redes de interlocução informais que vinham ganhando corpo desde, pelo menos, as últimas décadas do século XIX.

\footnotetext{
${ }^{4}$ Ver, entre outros estudos do autor, BAKHTIN, 1981 e 2004. Ver ainda BRAIT, 2001.
} 
Rompidos os vínculos que nos prendiam à dinastia lusa, muitas batalhas simbólicas foram desfechadas. E, na fase inicial da República, o jacobinismo antilusitanista estava em alta, a ponto de atingir

altas proporções durante o governo do marechal Floriano Peixoto (18911894). Um dos principais representantes dessa postura foi o romancista Raul Pompeia, fanático florianista. Para ele a dificuldade encontrada pela República para consolidar-se era devida à presença portuguesa na imprensa, nos negócios e mesmo na população da cidade. (CARVALHO, 2005, p. 249)

Efetivamente, com sua retórica lusófoba, esse jornalista atribuía a Portugal a responsabilidade pelo atraso que o Brasil amargava. Para Raul Pompeia, o paradigma da modernidade eram os Estados Unidos.

Em certos segmentos da imprensa carioca abriu-se espaço para o antilusitanismo. Como mostra Robertha Pedroso Triches (2007), em pesquisa que confere destaque ao jornal O Jacobino, entre fins dos Oitocentos e início dos Novecentos, nas representações sobre o imigrante, ele foi submetido a ridicularizações à medida que se formaram estereótipos a seu respeito. Nisso contou, e muito, a ação dos intelectuais jacobinos na alvorada da República brasileira, fenômeno que acompanhou a imigração massiva que converteu os portugueses na maior colônia estrangeira no Rio de Janeiro. No rastro da Revolta da Armada, no começo dos anos 1890, chegou a deflagrar-se um movimento de caça aos lusitanos que culminou com o apedrejamento e incêndio de estabelecimentos comerciais de sua propriedade. Apontados como bode expiatório de tudo o que havia de ruim, eles foram acusados, ao estilo de Orestes Barbosa, até de "inventores do chulé".5

Por sua vez, um intelectual de peso como Manoel Bonfim (2005), tanto em seu livro América Latina: males de origem, de 1905, quanto em sua atividade jornalística, criticou a característica espoliativa da colonização ocorrida nestes trópicos, seja sob o jugo espanhol ou português, ela que fora a expressão nua e crua de um "parasitismo depredador". ${ }^{6}$ Mas as coisas não paravam por aí. O jornalista, memorialista e literato Luiz

\footnotetext{
5 Cf. O Jacobino, 19 de janeiro de 1915, apud TRICHES, 2007, p. 13.

${ }^{6}$ Sobre esse autor, ver MATOS, 2015.
} 
Edmundo, com sua prosa afiada, revelou-se abertamente antilusitano, como demonstram suas crônicas reunidas, em 1938, nos três volumes de O Rio de Janeiro do meu tempo. Enquanto isso, o ensaísta e jornalista Antônio Torres (1957) não deixava por menos ao exteriorizar, em 1925, a sua aversão aos lusos e assumir, sem meias-palavras, sua "tamancofobia".

Nada disso, contudo, deve nos levar a fechar os olhos para movimentos em sentido contrário. Desde os primeiros tempos do Brasil pós-independência, surgiram iniciativas que buscavam forjar uma comunidade luso-brasileira. Dos dois lados do Atlântico, políticos e homens de letras, a exemplo de João do Rio, da banda de cá, e João de Barros, acolá, deram asas à imaginação na tentativa de impulsionar o projeto de construção de uma Lusitânia, ou uma Atlântida, nome de uma revista que editaram entre 1915 e 1920. Essa procura de aproximação, no mínimo cultural, entre Brasil e Portugal redundou na defesa do que viria a ser batizado de luso-tropicalismo, que teria como um de seus arautos Gilberto Freyre, fiador de uma visão positiva sobre a colonização portuguesa. ${ }^{7}$

No caso deste artigo, a ênfase, no entanto, é posta noutra direção. E o quadro que se delineava não se resumia ao antilusitanismo. Nele, o antifadismo estava igualmente presente, e, mais, ele provinha especialmente de vozes d'além mar. Desde pelo menos a segunda metade do século XIX, acumulavam-se críticas e manifestações de escárnio em relação ao fado no próprio país que, posteriormente, o elegeria como símbolo de sua identidade cultural. O rol dos seus detratores é extenso e engloba intelectuais de prestígio como o romancista Eça de Queirós, o crítico de arte António Arroio e Armando Leça, tido como um dos fundadores da Etnomusicologia em Portugal.

Seus opositores não perdoavam os supostos pecados de origem dessa "música torpe e obscena", por sua associação ao submundo da prostituição e da delinquência. ${ }^{8}$ Do alto de sua autoridade de escritor e bibliógrafo, Albino Forjaz de Sampaio (1911, p. 11) lavrava sua sentença condenatória sobre o fado: "é uma canção de vadios, um hino ou

\footnotetext{
7 Para maiores referências sobre esses assuntos, ver CASTRO, 2009, VENÂNCIO, 2012, GUARDIÃO, 2012, e GUIMARÃES e CABRAL, 2012.

${ }^{8}$ Sobre o assunto, ver a obra fundamental de Rui Vieira Nery (2012a, p. 171-178)), na qual ele discorre sobre "os primeiros críticos do Fado".
} 
desabafo de criminais. Apoteosa o crime, o calão, o degredo, a miséria, a prostituição, o hospital”. De quebra, ele deplorava seu estilo arrastado, monótono, "langoroso", que, menos do que uma canção, era mais um lamento. Evidentemente, essa enxurrada de críticas endereçadas ao fado e aos fadistas não passaria sem resposta. Ela suscitou o aparecimento de peças de defesa de grande importância, como o livro $O$ fado e seus censores, de 1912, no qual o dramaturgo, ensaísta e letrista Avelino de Sousa partia para o contra-ataque. 9

Conforme documenta Rui Vieira Nery em várias de suas obras, as iniciativas com vistas à reabilitação do fado começaram já nos anos 70 do século XIX. Simultaneamente, ele ia, aos poucos, dilatando seu universo de irradiação de maneira a abranger, à semelhança do que sucedeu com o samba, outros grupos e classes sociais que não apenas aqueles que Ihe deram origem. O fado penetrou ambientes "respeitáveis", ingressou, com força, no mundo dos discos e das emissoras de rádio, além de exibir sua pujança em teatros de revista, nos cafés, no cinema e no setor de edição musical. E, nesse passo, "a sua expansão para outros contextos sociais - desde o meio universitário coimbrão até ao do circuito do Teatro Musical ligeiro das classes médias lisboetas - o leva a abarcar igualmente outras temáticas e a incorporar outras referências culturais" (NERY, 2012b, p. 8-9). ${ }^{10}$

Em sua caminhada, o fado foi saltando inúmeros obstáculos e, enfim, credenciouse como um item comercial dotado de forte poder de sedução junto à indústria fonográfica portuguesa principalmente da década de 1920 em diante. ${ }^{11}$ Como ressalta Rui Vieira Nery (2012a, p. 253), "o total dos discos de intérpretes portugueses vendidos em

\footnotetext{
9 Sobre a reação dos defensores do fado, ver NERY, 2012a, p. 178-185. Os lances, de parte a parte, desse debate são retomados em NERY 2012b, cap. 1.

10 Daniel Gouveia, numa nota prévia do livro Poetas populares do Fado tradicional, defende, a propósito, a tese de que teria ocorrido uma "evolução" social e uma "dignificação" do Fado, pois se poderia “observar a evolução temática e poética do Fado, desde as histórias ultradramáticas à volta da pobreza, da prostituição, dos crimes e das navalhas, até a uma gradual elevação que aproximou o Fado da Poesia, ou esta daquele. Com vantagens. A dignificação do gênero não teria sido possível sem esta 'fuga para cima' ao proletarismo inicial, fazendo com que outros espaços sociais sentissem nas letras do Fado a capacidade de despertar emoções e sentimentos estéticos" (GOUVEIA e MENDES, 2014, p. 7).

${ }^{11}$ Essa situação ambivalente do fado - ao mesmo tempo depreciado por uns e valorizado por outros - e sua posição na indústria do disco lusitana são temas explorados por Leonor Losa (2013, esp. p. 129-138).
} 
1929 terá ascendido a mais de 67.000, dos quais a esmagadora maioria corresponde a gravações de Fado".

Nem por isso, em plenos anos 1930, havia se dissipado por completo a grossa camada de preconceitos que envolvia o fado. Como "música ligeira”, ele ecoava basicamente nas emissoras privadas, com a Rádio Clube Portuguesa à frente, porque a Emissora Nacional de Radiodifusão (ENR), rádio estatal imbuída de sua "missão educativa”, privilegiava a música erudita. ${ }^{12}$ E foi justamente pelo microfone da ENR que, numa sequência de oito palestras, Luiz Moita (1936) extravasou toda sua ojeriza ao fado, ao destilar preconceitos sociais e incriminá-lo como "canção de vencidos". O poeta popular e compositor A. Victor Machado, um homem do meio do fado e pelo fado, não tardou a responder em tom enérgico. E se perguntava em livro publicado em 1937: "Serão vencidos os que assim triunfam no seio da sociedade e da maioria da opinião pública?" (MACHADO, 2012 $2^{13}$ ).

Orestes Barbosa, à sua moda, como que se incorporava a esse debate que se desenrolava há mais de meio século. Instalado no lado de cá do Atlântico, ele, que também nutria propósitos de "higienização" e de "regeneração" temática do samba como escancarou à época em que se posicionou contra o samba "Lenço no Pescoço", de Wilson Batista ${ }^{14}$-, colocava na ordem do dia varrer para fora do país o fado e, se possível, os portugueses. Os argumentos com os quais forrava suas críticas tinham muito em comum com outros tantos brotados em solo lusitano.

\section{Orestes Barbosa, um antilusitano militante}

Como venho insistindo, repetidamente, o carioca Orestes Barbosa ${ }^{15}$ - misto de jornalista, poeta e boêmio -, sobressaiu-se na luta contra o fado. Ele, que já foi descrito

\footnotetext{
12 Sobre o assunto, ver SILVA e MOREIRA, 2010. Esclareça-se que, mais adiante, a emissora estatal reformulará parcialmente sua programação, numa tentativa de capturar ouvintes cuja preferência se direcionava para as estações particulares nas quais se alojava a "música ligeira".

13 Cf. p. 14 da edição original em fac-símile. Da reedição aqui mencionada consta um longo estudo introdutório de Rui Vieira Nery sobre "a construção da ideologia fadista castiça".

14 Sobre algumas das polêmicas desatadas acerca do samba e da necessidade de sua "higienização", ver PARANHOS, 2016, p. 75-79.

${ }^{15}$ A obra mais completa sobre a vida, paixão e morte de Orestes Barbosa é a de DIDIER, 2005.
} 
como nacionalista "até a raiz dos seus poucos cabelos" (MÁXIMO e DIDIER, 1990, p. 149), caracterizava-se por ser, acima de tudo, antilusitano. Parceiro de Noel Rosa em algumas canções ${ }^{16}$, Orestes celebrizou-se, na história da música popular brasileira, como o autor da letra de "Chão de estrelas", na qual se encontra, segundo o poeta Manuel Bandeira (apud DIDIER, 2005, p. 549), talvez o mais belo verso escrito até então no idioma português ("tu pisavas nos astros distraída").

Conhecido por suas tiradas pontiagudas, ele não costumava desperdiçar oportunidade de falar mal dos portugueses. Sua língua ferina estalava ao embaralhar fatos históricos com assuntos do cotidiano e ao eleger os donos de casas de pequeno comércio (como as vendas e os botequins) procedentes de Portugal como um dos seus alvos prediletos. Como quem escarnece das epopeias dos "grandes vultos" lusitanos da era das navegações, ele proclamava, em 1933, deixando escorrer uma dose de fel pelos cantos da boca: "Por minha parte, com a autoridade de brasileiro nato, garanto que não quero, nem nunca quis saber quem foi Vasco da Gama. Eu quero saber é quem põe água no leite..." (BARBOSA, 1978, p. 34). Na mesma toada, o poeta fizera pouco, oito anos antes, de Pedro Álvares Cabral: “um grande navegador, que a caminho das Índias vem dar com os costados na Bahia, eu passo..." (BARBOSA, 1925, p. 13).

Não era à toa que Orestes crivava de críticas Portugal e os portugueses. Eles, no seu entender - diferentemente de outros povos, a exemplo dos italianos ${ }^{17}$-, eram sinônimos de atraso de vida. A despeito das aparências em contrário, nem sempre, no entanto, o compositor desancara tudo o que vira na "terrinha", observação que se aplica igualmente ao fado. Em livro editado em 1923, em que desfia relatos de viagem a Portugal, ele se reportara ao caráter multifacetado desse gênero musical, meio pelo qual, a seu ver, os portugueses não somente cantavam suas emoções como resolviam seus problemas: "a alma dolente, é no fado que o português resolve tudo". Para Orestes, o

\footnotetext{
${ }^{16}$ Quatro no total, de acordo com os melhores biógrafos de Noel Rosa (MÁXIMO e DIDIER, 1990), das quais a mais famosa é o samba "Positivismo".

17 Orestes enaltecia, com todas as letras, o espírito empreendedor de capitalistas de outras nações e, já na Primeira República, tendia a identificar progresso com industrialização, concepção que impregnaria o vocabulário econômico-político-social brasileiro de décadas posteriores. Para ele, enquanto estrangeiros como os italianos "dão passos largos no comércio e nas indústrias", assumindo um comportamento “moderno", "o português ficou na venda e no botequim” (BARBOSA, 1925, p. 107).
} 

1923, p. 99-100). ${ }^{18}$

A temperatura de suas avaliações, porém, iria se elevar nos anos seguintes. Para isso concorreu, ao que tudo indica, a recepção nada calorosa, azeda mesmo, que as crônicas enfeixadas, em 1923, em Portugal de perto! tiveram naquele país, tanto que resultaram na cassação do diploma que Ihe fora outorgado como sócio-correspondente da Associação dos Trabalhadores de Imprensa. Seu sentimento de repugnância a Portugal e aos lusitanos atravessou, de princípio ao fim, O português no Brasil, obra lançada em 1925. Sua epígrafe é, por si só, bastante esclarecedora. Ela reproduz as últimas palavras atribuídas a Felipe dos Santos, a maior liderança da Revolta de Vila Rica (atual Ouro Preto), deflagrada, em 1720, contra a exploração econômica e o controle metropolitano nas regiões auríferas de Minas Gerais, o que o teria conduzido, no desfecho desse episódio, ao enforcamento e ao esquartejamento, num ato típico do teatro político da violência patrocinado pelo jugo português. O brado "Morro sem arrependimentos, certo de que a canalha que nos avilta será esmagada pelo patriotismo dos brasileiros!" como que serviria de epitáfio para Felipe dos Santos (BARBOSA, 1925, p. 7).

Orestes não se dispunha a firmar qualquer pacto com os lugares-comuns de fundo mítico e mistificador construídos sobre a "Pátria-mãe", a "Pátria-irmã" e a pretensa “amizade luso-brasileira”, uma “mentira”, uma “tapeação” (BARBOSA, 1925, p. 9 e 92). Por sinal, no primeiro parágrafo do prefácio do livro ele apontava suas armas: "Este livro, escrito sem ódio e sem amor, tem como objetivo único mostrar aos brasileiros o perigo que há em deixar o português solto, sem freio, no Brasil” (id., p. 9). Em O português no Brasil, Orestes oferecia ao leitor "provas" em profusão para a compreensão do seu

\footnotetext{
18 Entre os exemplos fornecidos sobre as modalidades e temas de fados, são listados os "envinagrados" (“Quando eu era pequenino/ Já dizia minha mãe:/ Tu tens cara de assassino/ E o teu pai tinha tambãe!”) e os "gastrônomos" ("Rapazes, quando eu morrer/ Leva-me devagarinho/ Ponde em cima do caixão/ Azeitona, pão e vinho") (BARBOSA, 1923, p. 104 e 109). Mais tarde, ele acrescentaria que até na hora da morte se explicitava a distância abissal existente entre o malandro carioca e o português. Um "malandro do morro" entoava em seu samba: "Amigos, quando eu morrer/ Não quero choro nem nada:/ Eu quero é ouvir um samba/ Ao romper da madrugada” (BARBOSA, 1978, p. 80).
} 
antilusitanismo. Sim, para ele, impunha-se o dever de "provar", "demonstrar" uma tese, fundada em juízos de valor que se amparavam em "fatos", estes concebidos sob um viés positivista. Sua obra seria, em suma, uma coleção de "páginas de estatística e história" (id., p. 51). Longe de se reduzir à retórica "de um jacobinismo delirante" ou de "uma patriotada de cavação", o poeta afirmava que sua prosa, em forma de reportagem, expunha "os dados desapaixonados da estatística". Daí não acolher injúrias, porque "só registrei fatos visíveis e provados" (id., p. 10-11). ${ }^{19}$

Ao farejar, por todos os lados, os problemas acarretados ao Brasil pelo português, Orestes se apegava ainda a dados, de natureza geral, contidos nos boletins semanais do setor de Estatística Demográfico-Sanitária, notadamente do serviço da Inspetoria de Fiscalização dos Gêneros Alimentícios. E, por conta própria, estabelecia íntima associação entre a inutilização de alimentos por motivo de saúde pública e a ação nefasta dos lusitanos. Sua conclusão era categórica: "não podendo mais matar o brasileiro no pelourinho, no tronco, na forca, nem no calabouço, o português mata falsificando a alimentação" (BARBOSA, 1925, p. 39).

Por essas e outras, ele despejava toda sua ira sobre a cabeça dos portugueses. Suas palavras soavam como um grito de guerra - "guerra justíssima" (BARBOSA, 1925, p. 127) - ao que procedia de Portugal, quer se tratasse de ideias ou de gentes. Pudera! Para Orestes, a presença dos lusos no Brasil equivalia a uma ação de lesa-pátria, ante a qual convinha que os brasileiros se pusessem em guarda, pois somente "quando o português for corrido, de uma vez, do comércio, da indústria, das letras, da política, do jornalismo e do funcionalismo, o Brasil será o país que nós sonhamos muito antes de 1822" (id.). Anos depois, ele protestaria contra o destino do ouro arrancado às minas brasileiras: "o nosso ouro! [...] Virou ouro do Porto, cidade que nunca teve mina de coisa nenhuma. [...] $\mathrm{O}$ nosso ouro, que o lusitano levou todo" (BARBOSA, 1978, p. 77). ${ }^{20}$

\footnotetext{
19 Na ótica do autor, apoiada na verificação dos dados do movimento anual na Casa de Detenção do Rio de Janeiro em 1924, uma prova dos nove contra o elemento luso aparecia na contribuição marcante da colônia portuguesa à criminalidade. E ele sentenciava: "o português tem, afinal, o primeiro lugar em alguma coisa no Brasil: na estatística criminal” (BARBOSA, 1925, p. 53).

${ }^{20}$ Em última análise, essa linha de pensamento crítico pode ser vinculada, ao menos parcialmente, à tese consagrada por Caio Prado Júnior (1972, p. 13-23) ao remontar à colonização nestes trópicos, sob o impulso da expansão ultramarina europeia, como uma empresa voltada para a exploração comercial.
} 
Como se raciocinasse em círculo, Orestes Barbosa chegava sempre ao seu ponto de partida. As histórias por ele costuradas se alimentavam de um fundamento comum: o português, que o jornalista enxergava com lentes de aumento, fora e continuava sendo o estorvo número um para o avanço do processo de civilização brasileira. Ele encarnava o “maior empecilho”, “um entrave”, “o maior inimigo” ao progresso do país, tragado que era pelo "rotinismo desolador" (BARBOSA, 1925, p. 9, 87 e 127).

Entre os fartos exemplos que arrolava, tanto daqui como d'além-mar, todos eles convergiam para uma conclusão que funcionava também como o motor de sua reflexão: Portugal, em contraste com o Brasil, "ainda não tem civilização” (BARBOSA, 1925, p. 43). Em seu texto mais extenso de O português no Brasil, quem ia para a berlinda era Lisboa. $\mathrm{E}$ ela, a lendária capital portuguesa tão decantada nos fados, mostrava-se, aos olhos de Orestes, como uma carne viva exposta à devoração crítica. Quase todas as referências que o autor acionava se prestavam para destilar seu sarcasmo (id., esp. p. 23-28). Com irrefreável contundência, ele tomava partido em favor da higienização, da civilização e da modernidade, ou melhor, do oposto ao que Lisboa representaria. A Orestes repugnava o cheiro exalado pela cidade, a começar pelas suas principais ruas: "a cidade toda cheira a peixe, a peixe vivo e a peixe frito", preparado nas calçadas por "mulheres imundas" cobertas por um monte de saias que "esconde[m] o sujo" (id., p. 23 e 117).

Que não se pense, entretanto, que esses problemas atingiam em cheio tão somente Lisboa ou Portugal. Os imigrantes portugueses, que constituíam, no Rio de Janeiro de Orestes Barbosa, a colônia estrangeira mais numerosa, transportariam para cá os seus vícios de origem. Para ele, como escreveu em “Biba a Baríola!", quando eclodiu a Revolta da Vacina, em 1904, o português não pestanejou: resistiu às medidas médicohigienistas adotadas pelas autoridades governamentais, por ser "contra a vacina" e "a favor da varíola”... (BARBOSA, 1925, p. 103).

Nesse contexto, ao colocar o fado sob sua alça de mira, o poeta disparava suas críticas de forma a não restar pedra sobre pedra. Ele detectava a existência, por assim dizer, de uma linha de continuidade entre Portugal, atraso e fado. É bem verdade que, como viria a ser endossado posteriormente, pelo menos em parte, por pesquisadores de música popular, Orestes, em Samba, apesar de contrapor tal gênero - tipificado como carioca na sua essência - ao fado, admitia a tese de que este nascera no Brasil: "foi a 
lamúria do forasteiro quem o criou. Mas ele era tão português, que não ficou aqui” (BARBOSA, 1978, p. 14). ${ }^{21}$

Como quem tapa os ouvidos diante das lamúrias do fado, o compositor partia logo para a esculhambação: "O fado é um arroto! O fado só fala em miséria. Em cadelas de rua. Em bacalhau. Em catres de hospital. É sempre a mesma lamúria: 'Minha mãe/ Minha mãe/ Minha mãe.' Rimando com tambãe" (BARBOSA, 1978, p. 80-81). No levantamento que realizei sobre fados gravados e lançados no Brasil ao longo dos anos 1930, canções como “Minha mãe”, com Isalinda Seramota, "Carta à minha mãezinha” e "Minha mãezinha”, ambas com Manuel Monteiro, "Amor da mãe", com Maria Albertina, "Carta a minha mãe", com Américo Ferreira, "Mãe do soldado", com José Lemos, e "Carinhos de mãe”, com Nicolau Gomes Cunha, por certo só reforçavam a opinião de Orestes Barbosa. E não é preciso maior exercício de imaginação para supor qual seria sua avaliação do fado "A morte da ceguinha", interpretado por Manuel Monteiro...

\section{O fado nestes trópicos}

Nem era sem quê nem por quê a preocupação de Orestes Barbosa com a ressonância do fado por estes trópicos. Ao calibrar o foco de uma investigação preliminar sobre a produção fonográfica nas primeiras décadas do século XX e pôr na mira os fados gravados no Brasil, evidenciou-se que o período compreendido entre 1930 e 1939 corresponde, em linhas gerais, ao seu momento de maior difusão no país.

\footnotetext{
${ }^{21}$ Ver, sobre o assunto, três estudos de José Ramos Tinhorão: um sobre o lundu, a fofa e o fado nos séculos XVIII e XIX (TINHORÃO, 1988), outro sobre o fado como "dança do Brasil” (id., 1994) e mais um sobre o intercâmbio entre Brasil e Portugal na área da cultura popular (id., 2001). Visto como descendente do mesmo tronco do qual brotou o lundu, o fado é aí identificado como "dança de origem negro-brasileira destinada a virar canção em Portugal" (id., 2001, p. 138). Por outro lado, num ensaio sobre "O enigma do ‘fado' e a identidade luso-afro-brasileira”, o pesquisador português José Machado Pais reafirma que, "se o fado é um símbolo da identidade lusa, a história do fado mostra-nos que as suas raízes se encontram num Brasil africano". Ao complexificar a análise desse fenômeno musical, o sociólogo salienta, no entanto, que ele é o resultado de um tráfego de musicalidades múltiplas, produto "de um verdadeiro caldeamento musical", o que explicaria o fato de o fado ter "várias pátrias" (PAIS, 2001, p. 236, 228 e 238). Ao abordar a questão, o historiador e musicólogo Rui Vieira Nery esclarece que registros de viajantes, por volta de 1820, já chamavam a atenção para "o caráter assumidamente brasileiro deste Fado dançado. [...] Igualmente é bem sublinhada a origem africana da dança", tida como "voluptuosa", quando não "imoral”. Contudo, ele comenta: "Este Fado dançado no Brasil colonial está longe ainda de ser o Fado português, apesar de constituir inequivocamente o núcleo duro da sua origem" (NERY, 2012a, p. 37-38).
} 
E, nos anos 1930, ninguém registrou tantos fados em discos no Brasil quanto dois portugueses: um Manuel (Monteiro) e um Joaquim (Pimentel). O cetro de o rei do fado pertence, sem dúvida, a Manuel Monteiro, que, quem diria, viraria verbete no Dicionário Houaiss/Ilustrado: Música Popular Brasileira (ALBIN, 2006, p. 494). Nascido em Cimbres, Portugal, em 1909, ainda adolescente ele se transferiu, com sua família, para o Rio de Janeiro, onde morreu em 1990. Sua estreia na vida artística ocorreu no início da década de 1930 no "Programa Luso-brasileiro", da Rádio Educadora.

Naqueles tempos, não eram raros programas do tipo, dirigidos em particular à colônia portuguesa radicada na capital da República. ${ }^{22}$ A carreira do cantor (excepcionalmente compositor) decolou, sobretudo, entre 1933 e 1935, a julgar pela quantidade de fonogramas gravados nesses três anos, 37 ao todo. ${ }^{23}$ Reconhecido como o primeiro intérprete lusitano a ser bem-sucedido em terras brasileiras, acendeu, como não poderia deixar de ser, a fúria de Orestes Barbosa contra ele (DIDIER, 2005, p. 341 e 372).

No rol de gêneros que compunham o cardápio musical de Manuel Monteiro sobressaíam os fados, seguidos de viras e marchas, sem falar de canções carnavalescas de autoria de compositores nacionais. Seu "primeiro grande sucesso foi o fado 'Santa Cruz"” (ALBIN, 2006, p. 494), lançado em 1933. Manuel se converteu numa referência nada desprezível no cenário artístico brasileiro. Prova disso é que, em 1935, foi uma das estrelas do filmusical Alô, alô, Brasil, dividindo espaço, no elenco, com pesos-pesados da música popular brasileira, como Carmen Miranda, Francisco Alves, Sílvio Caldas, Mário Reis, Ari Barroso, Almirante, Custódio Mesquita e Aurora Miranda. ${ }^{24}$ Por sinal, o cartaz desse filme anunciava que dele "fazem parte os melhores elementos artísticos do rádio".

\footnotetext{
22 Eles podiam ser ouvidos também em São Paulo, onde o primeiro programa dedicado a canções lusitanas, “Horas portuguesas", era transmitido nessa época pela Rádio Educadora Paulista. Sobre a relação entre o fado e o rádio paulista, ver CANTERO, 2013, livro no qual, aliás, são disponibilizadas informações mais detalhadas sobre a carreira de Manuel Monteiro, Joaquim Pimentel e muitos outros artistas que encontraram no fado seu meio de expressão artística prioritário. Sobre a repercussão do fado ao longo do século XX em Santos, cidade portuária de significativo contingente de imigrantes lusos, ver VALENTE, 2008.

${ }^{23}$ Esta e outras informações subsequentes dessa natureza foram contabilizadas por mim com base no que figura em SANTOS et al., 1982, v. 2.

${ }^{24}$ Embora se achem, em diversas fontes, dados desencontrados sobre Alô, Alô, Brasil, ele chegou às telas, de fato, no começo de 1935. Ver, por exemplo, o noticiário jornalístico (Correio Paulistano, São Paulo, 13 de fevereiro de 1935) e a informação disponível em: <http://carmen.miranda.nim.br/aloaloz.htm/>. Acesso em 15 de agosto de 2011.
} 
E Manuel Monteiro, impulsionado pelo filme, emplacou um sucesso retumbante, a marcha "Salada portuguesa", mais conhecida pelo nome de "Caninha verde".

Na contabilização que efetuei dos fados transpostos para os discos entre 1930 e 1939, eles alcançaram a cifra de 172 fonogramas ${ }^{25}$, considerando-se a identificação dos gêneros musicais nas etiquetas dos $78 \mathrm{rpm}$. Aí predominava, com larga folga, a nomenclatura fado, se bem que, vez por outra, surgiam as denominações fado-canção (6) e fado-marcha (3). ${ }^{26} \mathrm{Na}$ cabeça da fila dos fadistas estava Manuel Monteiro, com 45 fonogramas, vindo a seguir Joaquim Pimentel, intérprete e compositor eventual (com 29), cuja carreira no mundo dos discos deslanchou entre 1935 e 1939. No terceiro posto (com 20) despontava José Lemos, enquanto cabia à cantora (compositora bissexta) Isalinda Seramota (com 15) o quarto lugar.

Uma imensa gama de cantores, cantoras, grupos musicais e instrumentistas (vários deles ancorados na guitarra, instrumento tradicional usado no fado) completava essa relação. Listados aqui em ordem alfabética, eram eles: A. F. da Conceição, Amélia Borges Rodrigues, Ana de Albuquerque Melo, Anita Gonçalves, Antônio Lopes, Artur Castro, Benício Barbosa, Berta Cardoso, Carlos Campos, Céu da Câmara, Desafiadores do Norte, Esmeralda Ferreira, Eugênio Noronha, Fábia Gil, Francisco Pezzi, H. da Conceição, Henrique Costa, Henrique Xavier Pinheiro, Horácio Rodrigues, Ivone Guedes, João Fernandes, Joaquim Seabra, José Galante, Maria Albertina, Maria do Carmo, Mirandella, Nicolau Gomes Cunha, Santos Carvalho, Stella Gil e Zaíra de Oliveira. ${ }^{27}$

Disso tudo decorre que o fado nem de longe passava em brancas nuvens na produção fonográfica do Brasil. E essa reverberação da música portuguesa fora do espaço no qual se aclimatara irritava profundamente Orestes Barbosa. Como guardião de uma política nacionalista de eterna vigilância, ele se indignava com a "macaqueação".

\footnotetext{
${ }^{25}$ Excluí deliberadamente desse cálculo umas poucas reproduções das mesmas gravações.

${ }^{26}$ Retomo aqui uma observação de fundo metodológico. Não ignoro que, por mais que as etiquetas dos discos $78 \mathrm{rpm}$ pudessem fornecer indicadores seguros para o enquadramento das canções sob um ou outro gênero musical, nem sempre elas eram plenamente confiáveis. Acrescente-se a isso que, apesar do valiosíssimo trabalho empreendido pelos organizadores da Discografia brasileira $78 \mathrm{rpm}$, em determinados casos - ainda que estatisticamente pouco relevantes - foi-lhes impossível obter os dados (completos ou não) sobre todos os discos gravados/lançados nos anos 1930.

27 Numa próxima etapa da pesquisa em curso, eu me deterei, mais especificamente, na análise dos fonogramas que divulgaram a produção fadista no Brasil, algo que foge aos objetivos deste artigo.
} 
Macaquear era, aliás, um verbo corrente no vocabulário empregado por Orestes para exprimir sua repulsa ao "servilismo" para com o estrangeiro.

De Portugal, como vimos, não existiria coisa alguma no que os brasileiros devessem se espelhar. De lá, para Orestes, praticamente não provinha nada que merecesse ser exaltado. E se alguém o questionasse sobre um dos símbolos do samba, Carmen Miranda, natural de Marco de Canaveses, Portugal, ele tinha a resposta na ponta da língua: como se Carmen houvesse nascido portuguesa por acidente geográfico, Orestes a definia como "uma sambista carioca". Ela desembarcara no Brasil com um ano de vida e teria sentido de perto, no corpo e na alma, a capacidade do Rio de Janeiro em forjar as pessoas à sua imagem e semelhança. De acordo com o autor de Samba, "ela, em verdade, é uma autêntica figura do meio, do meio que lhe absorveu, do ambiente que a plasmou, dando-nos mais um exemplo da força trituradora do Rio, que refina, como numa usina, os elementos aportados ao nosso torrão" (BARBOSA, 1978, p. 59). ${ }^{28}$

Além da presença dos portugueses e do fato na produção discográfica, eles se destacavam também nas companhias de teatro de revista lusitanas que aqui se exibiam com frequência, o que abriu caminho para o sucesso de vedetes da "terrinha" como Luiza Santanela. Isso culminará, mais adiante, inclusive com o surgimento de artistas com “sinais trocados": de um lado, Maria da Graça, nascida em Moçambique, então colônia de Portugal, caiu de boca no samba; de outro, para horror de Orestes, Olivinha Carvalho, que veio ao mundo em 1930, em Santos, acabaria por se dedicar acima de tudo ao fado, ela que estrearia no teatro de revista aos seis anos, conduzida pelas mãos de Joaquim Pimentel. Urgia pôr um paradeiro nesse estado de coisas. Daí o combate sem tréguas de Orestes Barbosa ao fado, aos fadistas e aos portugueses em geral.

\footnotetext{
${ }^{28}$ A "força trituradora" do Rio de Janeiro seria responsável, igualmente, por proezas como a conversão do lutador de boxe Kid Pepe (nome de guerra do italiano Giuseppe Gelsomino) num típico malandro carioca, que, por sinal, assumiu o papel (muitas vezes contestado, diga-se de passagem) de compositor de sambas. Para Orestes Barbosa, ele até parecia "um filho do Salgueiro". Com os ciganos, complementava o jornalista, acontecera o mesmo, como atestava sua cota de contribuição ao samba (BARBOSA, 1978, p. 66 e 83).
} 


\section{O samba como escudo protetor da nação}

A exemplo do que se verificava em outros cantos do mundo, respiravam-se, no Brasil da década de 1930, ares saturados de nacionalismos de todas as espécies. O campo musical não se manteve alheio às concepções que reduziam o estrangeiro à encarnação do mal. Nesse momento de afirmação do samba como ícone musical da nacionalidade, a música popular que aqui se gravava incorporava especialmente o fox-trot, o tango e o fado, que eram, nessa ordem, os gêneros “estrangeiros" mais em voga. O samba, na contramão desses ritmos tidos como "alienígenas", seria o principal escudo destinado (fadado?) a proteger a nação diante da "conspurcação" de seus costumes musicais.

A batalha desencadeada por Orestes Barbosa contra o fado constituía parte de um todo. Outros compositores e intérpretes se engajaram, à sua moda, na luta contra as "más influências" oriundas do exterior. Estas se associavam ao peso econômico-políticocultural do império estadunidense, numa conjuntura em que sua música - amplificada pelo cinema falado e pelas empresas fonográficas - indicava para onde caminhava a humanidade com a emergência de uma nova potência hegemônica no sistema capitalista. No plano cultural, a reação nacionalista ao fox e à disseminação do inglês no linguajar cotidiano dos brasileiros se encorpou nos anos 1930.

"O fox-trot não se compara/ com o nosso samba, que é coisa rara", cantava Carmen Miranda em "Eu gosto da minha terra". Noel Rosa, ao deplorar, em "Não tem tradução", os efeitos que atribuía aos modismos gerados pelo cinema falado, torcia o nariz ante situações em que "o malandro deixou de sambar/ dando pinote/ e só querendo dançar o fox-trot". O fecho de seu samba, com a criatividade que Ihe era peculiar, sintetizava à perfeição seu ponto de vista nacionalista:

Amor, lá no morro, é amor pra chuchu

As rimas do samba não são "I love you"

Esse negócio de "alô", "alô, boy"

"Alô, Johnny"

Só pode ser conversa de telefone ${ }^{29}$

\footnotetext{
${ }^{29} \mathrm{Em}$ "Tarzan (o filho do alfaiate), Noel Rosa tornava a investir, sarcasticamente, contra a moda de jovens de classe média que, na esteira da onda cinematográfica hollywoodiana, cultivavam a imitação de Tarzan, recheando de algodão as ombreiras dos paletós.
} 
Assis Valente, compositor da maior importância na década de 1930, era também portador de uma visão nacionalista que, à semelhança de Noel Rosa, se distanciava do nacionalismo de extração oficial e enaltecia os artefatos culturais de origem popular. ${ }^{30} \mathrm{Na}$ sua ótica, como se ouvia na marcha "Good-bye", interpretada por Carmen Miranda, a mania do inglês (quando não a do francês) que começava a invadir a linguagem do dia a dia não se afinava com os nossos hábitos:

Good-bye, good-bye, boy

Deixe a mania do inglês

Fica tão feio para você

Moreno frajola

Que nunca frequentou

As aulas da escola

Muitos outros exemplos poderiam ser apresentados aqui, envolvendo outras canções e outros compositores, assim como os enlaces entre música, letra e performance instrumental e vocal. ${ }^{31}$ Todavia, para os fins deste texto, parece-me suficiente o que já foi exposto. Trata-se de evidenciar que a resistência frente aos "ritmos estrangeiros" integrava um movimento de afirmação do samba como gênero "tipicamente nacional" e dos sambistas como artistas patenteados para criação do samba. Afinal, um sentimento de orgulho se apossava deles, diplomados que eram na escola do samba, como foi proclamado em diversas composições, uma delas assinada por Assis Valente, "Minha embaixada chegou", sucesso na voz de Carmen Miranda:

\footnotetext{
30 Um de seus sambas mais conhecidos, "Brasil pandeiro" celebrava, alegremente, o samba como traço definidor de nossa singularidade musical.

31 Uma análise mais abrangente e mais matizada sobre esse processo de lutas de representações forçosamente deve admitir que nem todos os sambistas brasileiros se sintonizavam com a perspectiva nacionalista representada por Noel Rosa, Assis Valente, Orestes Barbosa e outros mais. Para além disso, o aprofundamento do tema implica não se restringir às letras das canções, quando mais não seja porque estas não se resumem a documentos escritos, razão pela qual é indispensável reconhecer sua condição de documentos sonoros umbilicalmente ligados às performances que lhes conferem sentido. Sobre esses dois aspectos, ver o capítulo "A invenção do Brasil como terra do samba: os sambistas e sua afirmação social” (PARANHOS, 2016, p. 47-88), no qual a temática deste tópico é aprofundada, bem como o artigo em que discuto questões metodológicas acerca dos cruzamentos entre História e música popular, valendo-me de aportes teóricos da História Cultural (id., 2004).
} 
Nesse contexto, o fado, à maneira do fox-trot e do tango, era uma espécie de “inimigo nacional”, uma doença cujo antídoto consistiria, acima de tudo, na produção e na propagação do samba. No fundo, esses gêneros "alienígenas", dialeticamente serviam - pela relação de oposição que se estabeleceu com eles - à causa nacionalista. Como expressão prática da "unidade dos contrários", sua existência era fundamental para alimentar a exaltação do que se considerava como essencialmente brasileiro. E o fado, pendurado numa das pontas dessa gangorra, era um dos alvos da artilharia de nacionalistas como Orestes Barbosa. Ora, o Brasil, "terra do samba e pandeiro”, como ressaltava Ari Barroso em “Aquarela do Brasil”, tinha uma feição musical própria. Tanto que, segundo as concepções sustentadas pelos defensores da identificação entre samba e nação, os brasileiros poderiam afirmar, em alto e bom som, que "em minhas veias corre sangue a batucar". 32

\footnotetext{
${ }^{32}$ Lanço mão, aqui, de uma citação, inteiramente fora de seu contexto original, de um verso de "O sangue não nega", de Luiz Melodia e Ricardo Augusto, composição da década de 1980, quando o "pérola negra" do Estácio respondia àqueles que o acusavam de não fazer sambas, apesar de ser negro e haver nascido no Morro de São Carlos.
} 


\section{Referências bibliográficas}

ALBIN, Ricardo Cravo (Coord.). Dicionário Houaiss ilustrado: música popular brasileira. Rio de Janeiro: Paracatu, 2006.

BAKHTIN, Mikhail. Problemas da poética de Dostoiévski. Rio de Janeiro: Forense Universitária, 1981.

BAKHTIN, Mikhail. Marxismo e filosofia da linguagem. 11. ed. São Paulo: Hucitec, 2004.

BARBOSA, Orestes. Portugal de perto! (Crônicas). Rio de Janeiro: Jacintho Ribeiro dos Santos (ed.), 1923.

BARBOSA, Orestes. O português no Brasil. Rio de Janeiro: edição do autor, 1925.

BARBOSA, Orestes. Samba: sua história, seus poetas, seus músicos e seus cantores 2. ed. Rio de Janeiro: Funarte, 1978.

BONFIM, Manoel. América Latina: males de origem. Rio de Janeiro: Topbooks, 2005.

BOURDIEU, Pierre. O poder simbólico. 5. ed. Rio de Janeiro: Bertrand Brasil, 2002.

BRAIT, Beth (Org.). Bakhtin, dialogismo e construção do sentido. Campinas: Editora da Unicamp, 2001.

CANTERO, Thais Matarazzo. Fado no Brasil: artistas e memórias. São Paulo: ABR, 2013.

CARVALHO, José Murilo de. Pontos e bordados: escritos de história e de política. Belo Horizonte: Editora UFMG, 2005.

CASTRO, Zília Osório de. Do carisma do Atlântico ao sonho da Atlântida. In: GUIMARÃES, Lucia Maria Paschoal (Org.). Afinidades atlânticas: impasses, quimeras e confluências nas relações luso-brasileiras. Rio de Janeiro: Quartet/Faperj, 2009, p. 57-87.

CHARTIER, Roger. A história cultural: entre práticas e representações. Lisboa-Rio de Janeiro: Difel/Bertrand Brasil, 1990.

DIDIER, Carlos. Orestes Barbosa: repórter, cronista e poeta. Rio de Janeiro: Agir, 2005.

EDMUNDO, Luiz. O Rio de Janeiro do meu tempo. Rio de Janeiro: Imprensa Nacional, 1938. (3 vs.). 
FOUCAULT, Michel. Estética, literatura e pintura, música e cinema. 2. ed. Rio de Janeiro: Forense Universitária, 2009.

GRAMSCI, Antonio. Cadernos do cárcere, v. I: Introdução ao estudo da Filosofia. A filosofia de Benedetto Croce. 2. ed. Rio de Janeiro: Civilização Brasileira, 2001.

GOUVEIA, Daniel e MENDES, Francisco. Poetas populares do fado tradicional. Lisboa: Imprensa Nacional-Casa da Moeda, 2014.

GUARDIÃO, Ana Filipa. "Império moral e cultural": a grande lusitânia sob a perspectiva de Consiglieri Pedroso. In: SARMENTO, Cristina Montalvão e GUIMARÃES, Lucia Maria Paschoal (Coords.). Culturas cruzadas em português: redes de poder e relações culturais (Portugal-Brasil, séculos XIX-XX), v. Il: Influências, ideários, periodismo e ocorrências. Coimbra: Almedina, 2012, p. 131-153.

GUIMARÃES, Lucia Maria Paschoal e CABRAL, Thais Pimentel. Da teoria ao discurso da memória vívida: breves reflexões sobre o luso-tropicalismo. In: SARMENTO, Cristina Montalvão e GUIMARÃES, Lucia Maria Paschoal (Coords.). Culturas cruzadas em português: redes de poder e relações culturais (Portugal-Brasil, séculos XIX-XX), v. II: Influências, ideários, periodismo e ocorrências. Coimbra: Almedina, 2012, p. 183-204.

LOSA, Leonor. Machinas fallantes: a música gravada em Portugal no início do século XX. Lisboa: Tinta da China, 2013.

MACHADO, A. Victor. Ídolos do fado. 2. ed.: Lisboa: Imprensa Nacional-Casa da Moeda, 2012.

MATOS, Sergio Campos. Manoel Bonfim e Oliveira Martins: olhares cruzados sobre Portugal e o Brasil. In: SARMENTO, Cristina Montalvão e GUIMARÃES, Lucia Maria Paschoal (Coords.). Culturas cruzadas em português: redes de poder e relações culturais (Portugal-Brasil, séculos XIX-XX), v. III: Arte, educação e sociedade. Coimbra: Almedina, 2015, p. 41-65.

MÁXIMO, João e DIDIER, Carlos. Noel Rosa: uma biografia. Brasília: Linha Gráfica/Editora UnB, 1990.

MOITA, Luiz. O fado, canção dos vencidos: oito palestras na Emissora Nacional. Lisboa: s./ed., 1936.

NERY, Rui Vieira. Para uma história do fado. 2. ed. Lisboa: Imprensa Nacional-Casa da Moeda, 2012a. 
NERY, Rui Vieira. Os Ídolos do Fado e a construção da ideologia fadista castiça. In: MACHADO, A. Victor. Ídolos do Fado. 2. ed.: Lisboa: Imprensa Nacional-Casa da Moeda, 2012, p. 11-65.

PAIS, José Machado. Vida cotidiana: enigmas e revelações. São Paulo: Cortez, 2001.

PARANHOS, Adalberto. A música popular e a dança dos sentidos: distintas faces do mesmo. ArtCultura, Uberlândia, Edufu, n. 9, p. 22-31, jul./dez. 2004.

PARANHOS, Adalberto. O roubo da fala: origens da ideologia do trabalhismo no Brasil. 2. ed. São Paulo: Boitempo, 2007.

PARANHOS, Adalberto. Os desafinados: sambas e bambas no "Estado Novo". São Paulo: Intermeios/CNPq/Fapemig, 2016.

PRADO JÚNIOR, Caio. História econômica do Brasil. 15 ed. São Paulo: Brasiliense, 1972.

SAMPAIO, Albino Forjaz de. Prosa vil. Lisboa: Empresa Literária Fluminense, 1911.

SANTOS, Alcino, BARBALHO, Gracio, SEVERIANO, Jairo e AZEVEDO, M. A. de (Nirez).

Discografia brasileira 78 rpm - 1902-1964. Rio de Janeiro: Funarte, 1982, v. 2.

SILVA, Manuel Deniz e MOREIRA, Pedro Russo. "O essencial e o acessório": práticas e discursos sobre música ligeira nos primeiros anos da Emissora Nacional de Radiodifusão (1933-1949). In: DOMINGOS, Nuno e PEREIRA, Victor (Dirs.). O Estado Novo em questão. Lisboa: Edições 70, 2010, p. 111-130.

SOREL, George. Reflexões sobre a violência. São Paulo: Martins Fontes, 1992.

TINHORÃO, José Ramos. Os sons dos negros no Brasil - cantos, danças, folguedos: origens. São Paulo: Art, 1988.

TINHORÃO, José Ramos. Fado: dança do Brasil, cantar de Lisboa - o fim de um mito. Lisboa: Caminho, 1994.

TINHORÃO, José Ramos Cultura popular: temas e questões. São Paulo: Editora 34, 2001.

TORRES, Antônio. As razões da Inconfidência. Belo Horizonte: Itatiaia, 1957. 
VALENTE, Heloísa (Org.). Canção d'além-mar: o fado e a cidade de Santos. Santos: Realejo/Musimid, 2008.

VENÂNCIO, Giselle Martins. Uma festa luso-brasileira? As comemorações do tricentenário da morte de Luiz de Camões no Rio de Janeiro em 1880. In: SARMENTO, Cristina Montalvão e GUIMARÃES, Lucia Maria Paschoal (Coords.). Culturas cruzadas em português: redes de poder e relações culturais (Portugal-Brasil, séculos XIX-XX), v. II: Influências, ideários, periodismo e ocorrências. Coimbra: Almedina, 2012, p. 27-52.

\section{Referências discográficas}

“A morte da ceguinha" (J. G. Fernandes e L. Marques), Manuel Monteiro. 78 rpm Odeon, 1934.

“Amor da mãe" (C. Ramos e A. Neves), Maria Albertina. 78 rpm Victor, 1934.

“Aquarela do Brasil” (Ari Barroso), Francisco Alves. 78 rpm Odeon, 1939.

"Brasil pandeiro" (Assis Valente), Anjos do Inferno. 78 rpm Columbia, 1941.

“Carinhos de mãe" (Abel D’Almeida), Nicolau Gomes Cunha. 78 rpm Columbia, s./d. (provavelmente 1937).

“Carta a minha mãe" (Antônio Pires e H. Pessoa), Américo Ferreira. 78 rpm Columbia, s./d. (provavelmente 1934).

“Carta a minha mãezinha” (Júlio Gonçalves Dias), Manuel Monteiro. 78 rpm Odeon, 1934.

“Chão de estrelas” (Silvio Caldas e Orestes Barbosa), Silvio Caldas. 78 rpm Odeon, 1937.

"Eu gosto da minha terra" (Randoval Montenegro), Carmen Miranda. 78 rpm Victor, 1930.

“Good-bye” (Assis Valente), Carmen Miranda. 78 rpm Victor, 1933.

"Lenço no pescoço" (Wilson Batista), Sílvio Caldas. 78 rpm Victor, 1933.

"Mãe do soldado" (A. Santelmo e Carlos Campos), José Lemos. 78 rpm Columbia, 1934.

“Minha mãe” (Marques Coelho), Isalinda Seramota. 78 rpm Odeon, 1931.

“Minha mãezinha" (J. Fernandes), Manuel Monteiro. 78 rpm Odeon, 1934. 
“Não tem tradução” (Noel Rosa), Francisco Alves. 78 rpm Odeon, 1933.

“O sangue não nega” (Luiz Melodia e Ricardo Augusto), Luiz Melodia. LP Felino, Ariola, 1983.

“Positivismo" (Noel Rosa e Orestes Barbosa), Noel Rosa. 78 rpm Columbia, 1933.

"Salada portuguesa" (Vicente Paiva e Paulo Barbosa), Manuel Monteiro. 78 rpm Odeon, 1935.

"Santa Cruz" (Caramés e Domingos Santos), Manuel Monteiro. 78 rpm. Odeon, 1933.

“Tarzan (o filho do alfaiate)" (Vadico e Noel Rosa), Almirante. 78 rpm Victor, 1936.

"Último desejo" (Noel Rosa), Aracy de Almeida. 78 rpm. Victor 1938.

“Último desejo" (Noel Rosa), António Zambujo. CD Rua da Emenda, Universal, 2014. 